\title{
Predictive value of early neuroimaging, pulsed Doppler and neurophysiology in full term infants with hypoxic-ischaemic encephalopathy
}

\author{
P Eken, M C Toet, F Groenendaal, L S de Vries
}

\begin{abstract}
To evaluate their prognostic value, five different non-invasive techniques were used on 34 full term infants with hypoxicischaemic encephalopathy (HIE) within six hours of delivery. Cranial ultrasonography, the resistance index (RI) of the middle cerebral artery obtained with Doppler ultrasonography, somatosensory evoked potentials (SEPs), visual evoked potentials (VEPs) and the cerebral function monitor (CFM) were used. According to the criteria of Sarnat, 11 infants developed mild, seven moderate, and 16 severe encephalopathy. The CFM had the highest positive (PPV $84.2 \%$ ) and negative predictive value (NPV 91.7\%). All but one of the infants with a continuous pattern had a good outcome. The CFM of 11 cases with a suppression-burst pattern changed to a continuous pattern over 24 to 48 hours in four infants, and was associated with a normal outcome in three. All five cases with an isoelectric CFM died. The SEPs also provided useful information (PPV $81 \cdot 8 \%$; NPV 91.7\%). VEPs were often delayed during the first hours or life and did not carry a poor prognosis in five of 14 cases (PPV 77.3\%). Both ultrasonography and Doppler RI were of little value, as they were almost always normal at this early stage.
\end{abstract}

In 34 full term infants with HIE, studied within 6 hours of life, the CFM and SEPs provided the most useful information about the expected course of encephalopathy and subsequent neurodevelopmental outcome.

(Arch Dis Child 1995; 73: F75-F80)

Keywords: hypoxic-ischaemic encephalopathy, Doppler ultrasonography, evoked potentials, cerebral function monitor.

Department of

Neonatology,

Wilhelmina Children's

Hospital, Utrecht, The

Netherlands

P Eken

M C Toet

F Groenendaal

L S de Vries

Correspondence to:

Dr Linda $S$ de Vries

Department of Neonatology,

Wilhelmina Children's

Hospital, Nieuwe Gracht

137, 3512 LK Utrecht, The

Netherlands.

Accepted 30 April 1995
The incidence of hypoxic-ischaemic encephalopathy (HIE) in full term infants is 2-9/1000. This has remained constant for the past four decades. ${ }^{1}$ Using the criteria of Sarnat and Sarnat ${ }^{2}$ to classify the degree of encephalopathy, $25-40 \%$ of the infants with a moderate encephalopathy and $90-100 \%$ of those with severe encephalopathy either die or develop major neurological sequelae. ${ }^{2-5}$ It often takes 12-24 hours for the clinical picture to evolve, and several studies have shown that early markers, such as Apgar scores, cord blood $\mathrm{pH}$, and delay in establishing regular respiration, have a limited role in predicting which infants will go on to develop moderate or severe encephalopathy. ${ }^{6-8}$

Trials with neuroprotective agents have already began in adults ${ }^{9}$ with cerebral hypoxiaischaemia and it is expected that they will also be started in the near future in newborn infants. ${ }^{10}$ Early identification of those infants most at risk of dying or developing severe neurological impairment is therefore of great importance.

The aim of this study was to perform cranial ultrasound, pulsed Doppler measurements, visual and somatosensory evoked potentials and cerebral function monitor recordings during the first six hours of life, to determine which test, or which combination of tests, would enable us to select, at a very early stage, those infants at risk of developing a major handicap.

\section{Methods}

Between January 1993 to January 199568 infants with a gestational age of between 37 and 42 weeks were admitted to the level III neonatal intensive care unit of the Wilhelmina Children's Hospital. HIE was defined according to the criteria of Sarnat. ${ }^{2}$ Although all patients in our hospital are outborn, 34 of these 68 infants were admitted immediately after delivery and were therefore studied within 6 hours of age.

The infants were diagnosed as having HIE when they developed the requisite clinical picture within 24 hours of delivery and when at least three of the following criteria were met:

(a) signs of intrauterine asphyxia, as indicated by late decelerations on fetal monitoring or by meconium staining of the amniotic fluid;

(b) arterial cord blood $\mathrm{pH}$ of $<7 \cdot 10$;

(c) delayed onset of spontaneous respiration;

(d) Apgar score of $<5$ at 5 minutes;

(e) multi-organ failure.

The infants were classified as having mild, moderate, or severe encephalopathy. ${ }^{2}$

\section{CRANIAL ULTRASOUND}

Ultrasonography was performed within six hours of delivery and subsequently daily during the first week and twice weekly thereafter until discharge, using an Ultramark-4 mechanical sector scanner with a rotating transducer (5-7.5-10 MHz crystals). The $7 \cdot 5$ and $10 \mathrm{MHz}$ transducer was used routinely. The findings were classified at 6 hours of age as normal or as abnormal when (i) areas of increased echogenicity were seen in the periventricular or subcortical white matter, 
(ii) in the cortical grey matter, or (iii) in the thalami and/or basal ganglia.

\section{RESISTANCE INDEX (RI) OBTAINED WITH DOPPLER ULTRASOUND}

Doppler signals were obtained with a $5 \mathrm{MHz}$ pulsed wave ATL duplex Doppler system. The transducer was placed between the eye socket and the ear, just above the zygoma, to obtain signals from the middle cerebral artery. The back-scattered Doppler signals were subjected to real-time spectral analysis and then displayed visually as a sonogram on a variable persistence monitor, and as an auditory signal. This method allowed the optimal signal to be obtained as maintained during the recording. When the image was stored the RI was calculated by analysing the maximum frequency envelope from at least five consecutive cardiac cycles to give peak or systolic frequency (S) and trough or diastolic frequency (D). This was repeated two to three times to ensure reproducibility. The RI was then derived from the equation: $R I=(S-D) / S$.

An RI above 0.55 was considered normal. An RI of less than 0.55 , a reversed diastolic flow, or an absent diastolic flow associated with a $\mathrm{PaCO}_{2}$ above $30 \mathrm{~mm} \mathrm{Hg}$ were considered abnormal.

SOMATOSENSORY EVOKED POTENTIALS (SEPS) SEPs were recorded with a Nihon Kohden Neuropack IV machine. $\mathrm{Ag} / \mathrm{AgCl}$ disc electrodes were used: the negative electrode on $\mathrm{C}^{\prime}$, the positive one on $\mathrm{Fz}$, and the neutral one on the lower arm. The impedance was less than $2 \mathrm{kOhms}$. Electrical stimuli of 0.1 millisecond in duration were delivered at a rate of one every
2 seconds. A hand-held device, placed on the ventral wrist overlying the median nerve, was used. The stimulation intensity was that required to produce a minimal thumb twitch. Recordings were obtained from the left somatosensory cortex, following stimulation of the right median nerve. Recordings were obtained from both hemispheres when a unilateral lesion was found on cranial ultrasound examination. A total of 50 responses was averaged through a bandpass of $2-100 \mathrm{~Hz}$. Each trial was repeated two to three times to ensure reproducibility. The analysis time took 200 milliseconds. The latency to peak of the first negative wave (N1) was measured according to the criteria of Desmedt $e t$ al. ${ }^{11}$ The normal data of Klimach and Cooke ${ }^{12}$ were used, as the same filter settings and stimulation time were used.

The SEPs were graded as abnormal when the latency fell outside the normal range, when the waveform was abnormal, which in all cases coincided with a delay in latency, or when a response could not be elicited.

VISUAL EVOKED POTENTIALS (VEPS)

VEPs were recorded with the same machine. The negative electrode was placed on $\mathrm{Fz}$, the positive one on $\mathrm{Oz}$, and the neutral one on the lower arm. The impedance was less than 5 kOhms. Red-light flash stimuli were delivered by an Amplaid LED-stimulator placed at a distance of $10-20 \mathrm{~cm}$ in front of the infant's eyes. Flashes of 10 milliseconds in duration were delivered at a rate of one every 2 seconds. A total of 50 responses was averaged through a bandpass of 2-100 Hz. Each trial was repeated two to three times to ensure reproducibility. Analysis time took 1000 milliseconds. The latency to peak of the first positive wave (P200)

Table 1 Results of 34 infants studied within six hours of life

\begin{tabular}{|c|c|c|c|c|c|c|c|c|c|}
\hline $\begin{array}{l}\text { Case } \\
\text { No }\end{array}$ & Sex & Grade & Ultrasound & $R I$ & $S E P$ & $V E P$ & $C F M$ & Outcome & Necropsy \\
\hline 1 & $\mathbf{M}$ & I & Normal & $0 \cdot 7$ & Normal & Delayed & Continuous activity & & \\
\hline 2 & $\mathrm{~F}$ & I & Normal & $\mathrm{AD} / \mathrm{CO} 2$ & Normal & Normal & & & \\
\hline 3 & $\mathrm{~F}$ & I & PVE & 0.6 & Normal & Normal & Continuous activity & & \\
\hline 4 & $\mathbf{F}$ & I & PVE & 0.7 & Normal & Delayed & Continuous activity & & \\
\hline 5 & $\mathrm{~F}$ & I & Normal & $0 \cdot 8$ & Delayed & Normal & Continuous activity & & \\
\hline 6 & $\mathbf{M}$ & I & PVE & 0.7 & Normal & Normal & Continuous activity & & \\
\hline 7 & $\mathbf{F}$ & I & Normal & 0.7 & Delayed & Normal & Continuous activity & & \\
\hline 8 & $\mathbf{M}$ & I & Normal & 0.8 & Normal & Normal & Continuous activity & Normal & \\
\hline 9 & $\mathbf{M}$ & I & Normal & $0 \cdot 7$ & Normal & Delayed & Continuous activity & & \\
\hline 10 & $\mathrm{~F}$ & I & Normal & $\mathrm{AD} / \mathrm{CO} 2$ & Normal & Normal & Continuous activity & & \\
\hline 11 & $\mathbf{M}$ & I & Normal & 0.7 & Delayed & Normal & Continuous activity & & \\
\hline 12 & $\mathbf{M}$ & II & IHF & $0 \cdot 7$ & Normal & Delayed & Continuous activity & & \\
\hline 13 & $\mathbf{F}$ & II & PVE & $0 \cdot 7$ & Normal & Normal & BS & & \\
\hline 14 & $\mathbf{M}$ & II & PVE & $0 \cdot 7$ & Delayed & Normal & BS & & \\
\hline 15 & $\mathbf{M}$ & II & PVE & 0.9 & Delayed & Normal & Continuous activity & Major handicap & \\
\hline 16 & $\mathbf{M}$ & II & PVE & $0 \cdot 7$ & Delayed & Normal & BS & Minor handicap & \\
\hline 17 & $\mathbf{M}$ & II & Normal & $0 \cdot 8$ & Normal & Delayed & $\mathrm{BS} / \mathrm{C}$ & Normal & \\
\hline 18 & $\mathbf{M}$ & II & TENT TEAR & $0 \cdot 7$ & Delayed & Delayed & CLV & & - \\
\hline 19 & $\mathrm{~F}$ & III & Normal & $\mathrm{AD}$ & & Delayed & BS/IE & & + \\
\hline 20 & $\mathrm{~F}$ & III & Normal & $0 \cdot 6$ & & Delayed & BS & & + \\
\hline 21 & $\mathrm{~F}$ & III & PVE & 0.7 & & Delayed & BS & & + \\
\hline 22 & $\mathbf{M}$ & III & Normal & 0.6 & & Absent & CLV & & + \\
\hline 23 & $\mathrm{~F}$ & III & Normal & - & Absent & Absent & - & & + \\
\hline 24 & $\mathbf{F}$ & III & Normal & 0.7 & & Absent & BS/IE & & - \\
\hline 25 & $\mathbf{M}$ & III & Normal & Reversed flow & & Absent & - & & + \\
\hline 26 & $\mathbf{M}$ & III & PVE & 0.6 & & Absent & IE & Died & - \\
\hline 27 & $\mathrm{~F}$ & III & Normal & 0.7 & Normal & Delayed & BS & & - \\
\hline 28 & $\mathbf{M}$ & III & PVE + THAL & 0.7 & Absent & Delayed & IE & & - \\
\hline 29 & $\mathbf{F}$ & III & Normal & - & Absent & Absent & BS & & - \\
\hline 30 & $\mathbf{M}$ & III & Normal & $\mathrm{AD} / \mathrm{CO} 2$ & Absent & Delayed & BS/IE & & - \\
\hline 31 & $\mathbf{M}$ & III & PVE + THAL & 0.8 & Delayed & Delayed & IE & & + \\
\hline 32 & $\mathbf{F}$ & III & Normal & $\mathrm{AD} / \mathrm{CO} 2$ & Absent & Delayed & CLV & & - \\
\hline 33 & $\mathbf{F}$ & III & PVE + THAL & 0.5 & Absent & Absent & IE & & + \\
\hline 34 & $\mathbf{M}$ & III & Normal & $0 \cdot 5$ & Absent & Absent & IE & & - \\
\hline
\end{tabular}

$\mathrm{PVE}=$ periventricular echodensities; $\mathrm{IHF}=$ increased echogencity around the interhemispheric fissure; $\mathrm{TENT}$ TEAR $=$ tentorial tear; $\mathrm{PVE}+\mathrm{THAL}=\mathrm{PVE}+$ thalamic densities; $\mathrm{AD} / \mathrm{CO} 2=\mathrm{AD}$ associated with $\mathrm{CO} 2<30 ;-=$ not done; $\mathrm{BS}=$ burst-suppression; $\mathrm{CLV}=$ continuous low voltage; $\mathrm{IE}=\mathrm{isoelectric}$. 
Table 2 Predictive value of different tests at less than 6 hours of age

\begin{tabular}{llllll}
\hline & $\begin{array}{l}\text { Ultrasonography } \\
(n=34)\end{array}$ & $\begin{array}{l}R I \\
(n=32)\end{array}$ & $\begin{array}{l}\text { SEP } \\
(n=34)\end{array}$ & $\begin{array}{l}\text { VEP } \\
(n=34)\end{array}$ & $\begin{array}{l}\text { CFM } \\
(n=31)\end{array}$ \\
\hline Sensitivity & $42 \cdot 1$ & $23 \cdot 5$ & $94 \cdot 7$ & $89 \cdot 5$ & $94 \cdot 1$ \\
Specificity & 60 & 100 & $73 \cdot 3$ & $66 \cdot 7$ & $78 \cdot 6$ \\
PPV & $57 \cdot 1$ & 100 & $81 \cdot 8$ & $77 \cdot 3$ & $84 \cdot 2$ \\
NPV & 45 & $53 \cdot 6$ & $91 \cdot 7$ & $83 \cdot 3$ & $91 \cdot 7$ \\
\hline
\end{tabular}

and the subsequent negative wave (N300) was measured according to the criteria of McCulloch and Taylor. ${ }^{13}$ The normal data of Taylor et $a l^{14}$ were used, as the same filter settings and stimulation rate were used.

The VEP was graded as abnormal when the P200 latency fell outside the normal range, when the waveform was abnormal, which in all cases coincided with a prolonged latency, or when no response could be elicited.

\section{CEREBRAL FUNCTION MONITOR (CFM)}

An amplitude integrated continuous electroencephalogram (EEG) recording, the cerebral function monitor (CFM 4640, Lectromed Devices Ltd), was applied. The CFM records a single channel EEG from two biparietal electrodes. The filtered signal is rectified, smoothed, and amplitude integrated before it is written out at slow speed $(6 \mathrm{~cm} /$ hour $)$ at the cot-side. ${ }^{15}$ Both the background activity and the presence of seizure activity were taken into account when analysing the data. The CFM was graded as normal when background activity was continuous and of normal voltage and when no seizure patterns were present. The CFM was graded as abnormal when background activity showed burst-suppression, continuous extremely low voltage (main activity below $5 \mu \mathrm{V}$ ), was flat (mainly isoelectric), or when seizure patterns were present. ${ }^{15}$

\section{ASSESSMENT OF NEURODEVELOPMENTAL OUTCOME}

The survivors were seen in the follow up clinic at 3, 9, 18, and 24 months of age. Assessment of outcome was made using the Griffith's mental developmental scale ${ }^{16}$ and items from the Amiel-Tison and Grenier evaluation ${ }^{17}$ and Touwen's findings. ${ }^{18} \mathrm{~A} \mathrm{DQ}$ below 85 on the Griffiths scale was considered abnormal and cerebral palsy was classified according to the criteria of Haberg et al. ${ }^{19}$

\section{SEP PAE I}

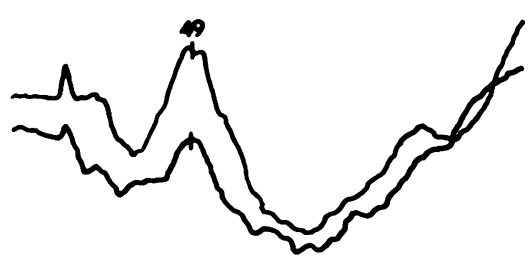

$3 \mathrm{hrs}$

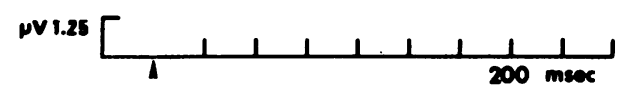

Figure 1 Normal N1 latency (49 milliseconds) at 3 hours of age in case 4.
Results

Table 1 summarises the ultrasound findings, the resistance indices and the electrophysiological findings (SEPs, VEPs, CFM) obtained within the first six hours of life, and the neurodevelopmental progress at the age of 6-24 months (median age 12 months) in the 34 subjects studied.

The predictive value of the different tests is summarised in table 2 .

\section{CRANIAL ULTRASONOGRAPHY}

No ultrasound abnormalities were noted in 20 cases. Only nine of these infants had a good outcome; the other 11 infants had severe encephalopathy and died.

Areas of increased echogenicity in the periventricular and/or subcortical white matter were present in nine cases. Two infants died, one had a major, one a minor handicap (DQ 84 ), and five had a good outcome.

Five cases had a different type of ultrasound abnormality. One showed an increase in echogenicity in the grey matter around the interhemispheric fissure, which subsequently evolved into a few small cysts. This child was normal at follow up. One child had blood above the cerebellum, suggestive of a tentorial tear, which was subsequently confirmed by computed tomography. This child died. The other three children had areas of increased echogenicity in the thalami and in the periventricular white matter and also died.

RI

RIs were available in 32 of the 34 cases. An RI of $>0.55$ was found in 28 cases. An absent diastolic flow, associated with a $\mathrm{PaCO}_{2}$ of $<30$ $\mathrm{mm} \mathrm{Hg}$ was found in four of these 28 infants. Fifteen infants had a normal outcome, one a major, one a minor handicap, and the remaining 11 died.

Only four infants with severe encephalopathy had an abnormal RI. One child had no diastolic flow while the $\mathrm{PaCO}_{2}$ was $31 \mathrm{~mm} \mathrm{Hg}$ at the time; one child had a reverse diastolic flow and the other two children had an RI of $<0 \cdot 55$. All four died.

SEPS

Twelve infants had a normal waveform and normal N1 latency. All but one of the infants had a good outcome (Fig 1). In the one infant who died no response could be elicited at 36 hours of age at which stage the CFM showed a status epilepticus. Eight of these 12 infants had mild, three moderate, and the child who died severe encephalopathy.

Eight infants had a delayed N1 latency. Two infants died, one developed a major, one a minor handicap, and four infants were normal at follow up. Three of these eight had mild, four moderate, and one severe encephalopathy.

In 14 infants no response could be obtained (fig 2). All had severe encephalopathy and all died. 
Figure 2 At 3 hours of age no cortical response could be elicited following stimulation of the median (274 milliseconds) was present but delayed (bottom) in case 19. nerve (top), while the P200

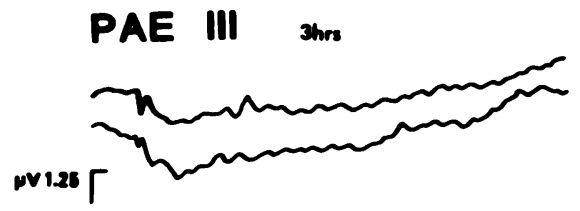

SFP

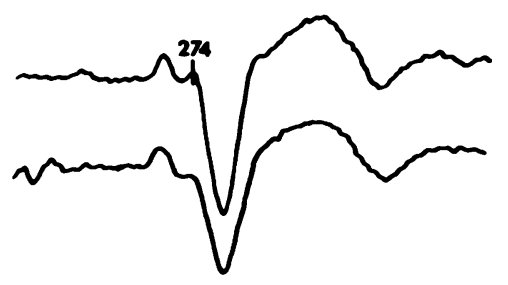

VEP

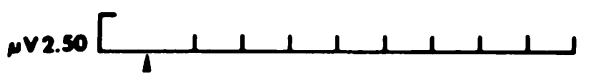

VEPS

Twelve infants had a reproducible response with a normal waveform and latency of the P200. All but two of the infants had a good outcome. One had a major and one a minor handicap. The infants with a good outcome all had mild encephalopathy, while the two with an abnormal outcome had moderate encephalopathy.

Fourteen infants had a delayed response. Nine infants died, one with moderate and eight with severe encephalopathy (fig 2). Five were normal at follow up, three had mild, and two moderate encephalopathy.

No response could be obtained in eight infants who all had severe encephalopathy; all died.

\section{CFM}

CFM was recorded in only 31 of the 34 infants, as the machine was not yet available when the first three infants were studied. Twelve infants had a continuous background activity of normal voltage. One infant could only be recorded between 4 and 6 hours of age as he had to be transferred to another neonatal intensive care unit for treatment with extracorporeal membrane oxygenation (ECMO). All infants except the infant treated with ECMO had a good outcome. Ten of the 12 infants had mild and two moderate encephalopathy. Nineteen infants had abnormal CFM patterns.

Three infants with a continuous but Figure 3 CFM recorded in case 17 between 3 and 6 hours of age, showing $a$ change from $a$ suppression-burst pattern to a continuous pattern.

PAE II

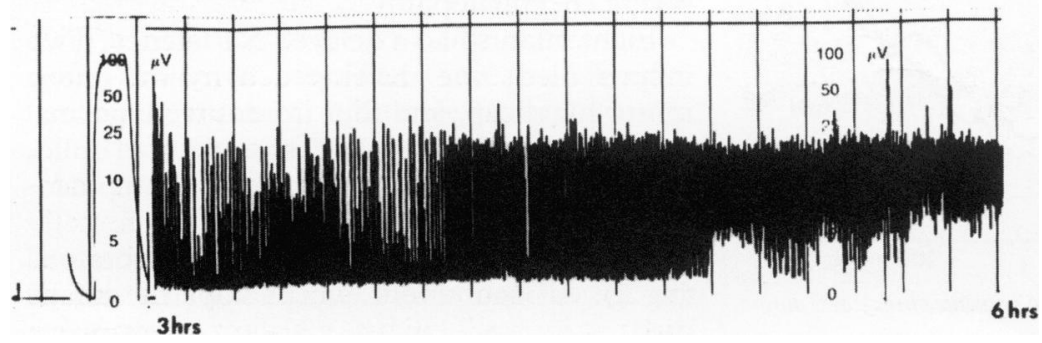

pattern by 6 hours of age. One infant had a minor handicap and three were normal at follow up. In one of the three with a normal outcome, the CFM pattern had changed to a continuous pattern by 6 hours of age (fig 3). The other five infants had a mainly isoelectric pattern and all died (fig 4).

\section{SEIZURES}

Repetitive subclinical seizures were found on the CFM in nine infants, three with moderate and six with severe encephalopathy. One of the three with moderate encephalopathy died, the other two were normal at follow up. All six with severe encephalopathy died.

In eight infants a loading dose of intravenous phenobarbitone $(20 \mathrm{mg} / \mathrm{kg})$ was administered while the CFM had been recording for at least 20 minutes. In four of the five infants with a mild encephalopathy the CFM pattern remained continuous, but a lower voltage was noted for 60-120 minutes (fig 5). In one of the five infants with mild and one with moderate encephalopathy a suppression-burst pattern occurred following administration of the drug (fig 5). In two infants with severe encephalopathy the suppression-burst pattern remained unchanged.

\section{CAUSE OF DEATH}

Seventeen infants died during the neonatal period, one with moderate and 16 with severe encephalopathy. In nine infants intensive care was withdrawn because of an isoelectric CFM and an isoelectric 16 channel EEG obtained after the first 24 hours of age. Post mortem histology was available for two of these nine infants; they showed extensive hypoxicischaemic damage. Two infants died due to multi-organ failure and both had a post mortem examination.

In the remaining six cases intensive care was withdrawn as the results of all the different tests described above remained severely abnormal on two or more occasions. Four of these six infants had a post mortem examination and extensive hypoxic-ischaemic changes were found on histology in all cases.

\section{Discussion}

During a two year period, 34 full term infants who met the criteria for HIE, were studied within six hours of birth. In all cases transfer to our neonatal intensive care unit had been requested. Most of the infants either developed mild $(n=11)$ or severe $(n=16)$ encephalopathy. Only seven infants developed moderate encephalopathy. This intermediate group is the most interesting one, as it is especially difficult to predict neurodevelopmental outcome in these infants using clinical examination alone, but referral is often delayed as spontaneous respiration is commonly established after resuscitation and referral is postponed until seizures, sometimes associated with apnoeic spells, develop between 12-24 hours of age. The neurodevelopmental out- 


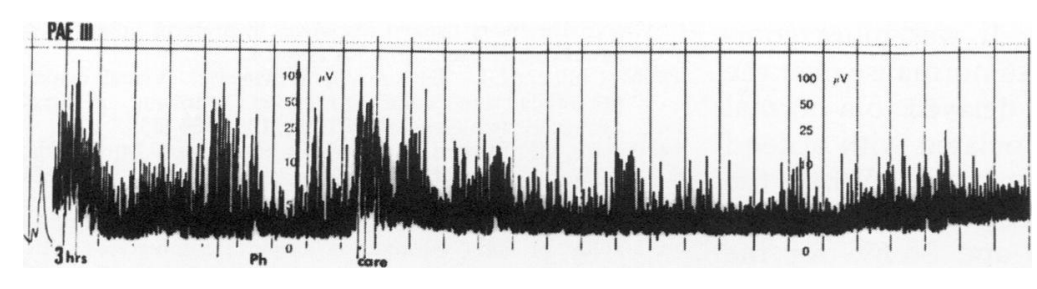

Figure 4 CFM recorded in case 19, showing a severe suppression-burst pattern, changing into an isoelectric pattern.

come of all 11 infants with mild encephalopathy was good. All 16 cases with severe encephalopathy died and two of the seven with moderate encephalopathy had an unfavourable neurological outcome. These findings agree with previous follow up studies. ${ }^{2-5}$

Five different tests were performed as soon as possible following admission and stabilisation of the infants. All tests had been shown to be good predictors of neurodevelopmental outcome, when performed during the first week, but only the CFM was recently used during the first 6 hours of life. ${ }^{1520-30}$ As expected, very little information was obtained from both cranial ultrasound as well as pulsed Doppler studies. Cranial ultrasound has been considered to be of little value in the full term infant with HIE ${ }^{31-34}$ and the use of neonatal magnetic resonance imaging (MRI) has been advocated instead. ${ }^{35-37}$ Some groups, using the $10 \mathrm{MHz}$ for visualisation of the cortex, have shown good agreement with computed tomography and MRI data. ${ }^{38-40}$ Most of the infants with severe encephalopathy developed severe changes on ultrasonography in the cortex and/or basal ganglia between 24-72 hours of age, and a good correlation was found of the ultrasound abnormalities and histological findings. ${ }^{40}$ As these ultrasound changes took several days to develop, ultrasonography is not useful for early identification of infants at risk of severe neurological sequelae.

The pulsed Doppler data were also of little predictive value. An absent diastolic flow was noted in a few cases, but was in all but one associated with a low $\mathrm{PaCO}_{2}$ at the time. In only one of the infants was a reverse flow seen during the diastole, which is an ominous sign
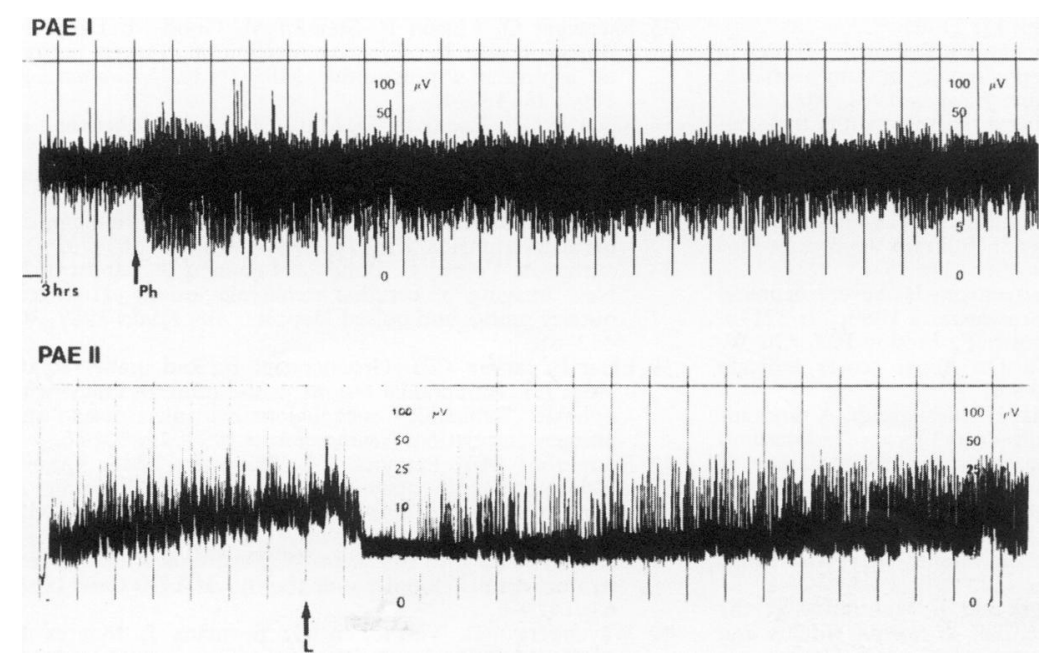

Figure 5 Effect of phenobarbitone (Ph, L) on the CFM is shown in an infant with mild (case 4) and an infant with moderate (case 14) encephalopathy. In the mild case a decrease of the minimum voltage is seen, while in the moderate case seizure activity changes to a suppression-burst pattern. in the absence of a patent ductus arteriosus. ${ }^{41}$ The high diastolic flow associated with an RI of $<0.55$, which usually develops between $12-24$ hours of age, was only present before 6 hours of age in two of our severe cases. A further nine out of 12 infants with severe encephalopathy, who survived beyond the first day of life, developed an RI of $<0.55$ after the 6 hours of age. As all five different examinations usually had to be performed within one to two hours, only $\mathrm{RI}$ measurements were performed because there was no time to study the effect of changing the $\mathrm{PaCO}_{2}$ on the diastolic flow.

Neurophysiology was very useful for predicting neurodevelopmental outcome during the first six postnatal hours. The sensitivity was more than $90 \%$ for both the CFM as well as the SEP and slightly lower for the VEP. The specificity was also best for the CFM and the SEP, being $78 \cdot 6$ and $73 \cdot 3$, respectively.

The CFM data agree with those of Hellström-Westas et al, ${ }^{15}$ although their specificity was slightly higher. This can partly be explained by the fact that we scored the CFM as early as possible. One of the infants improved from a suppression-burst pattern to a continuous pattern before 6 hours of age, which would change the specificity to $80 \%$. A continuous normal voltage pattern at 6 hours of age was a good prognostic indicator in 11 of 12 infants. In the one infant who did develop a major handicap the CFM was only recorded for a period of two hours, before he had to be referred for ECMO treatment. At 3 weeks of age small subcortical cysts were identified on ultrasonography and MRI. As in the study of Hellström-Westas et al, ${ }^{15}$ three of the 11 infants with a suppression-burst pattern were normal at 18-24 months of age. The remaining 16 infants with an abnormal background activity at 6 hours of age either died or had an abnormal neurodevelopmental outcome.

We were able to study the effect of a loading dose of phenobarbitone on the CFM in eight infants. In only one of the five children with mild encephalopathy was a suppression-burst pattern possibly induced by the drug, while a definite change in the CFM with a significantly lower minimum voltage was noted in the other infants, lasting between 60-120 minutes. In one child with moderate encephalopathy seizures were discontinued and a suppressionburst pattern was subsequently noted, and in the two infants with severe encephalopathy the suppression-burst pattern remained unchanged. So, although a change from a normal continuous background pattern into a suppression-burst pattern can occur, this seems to be rare in the infants with mild encephalopathy and it lasts only for a short period. Repetitive seizure activity was present in nine cases and was associated with a poor outcome in seven. Seizure activity was often noted not to develop till 6-24 hours of age.

A normal SEP or VEP obtained within 6 hours of age was also a good prognostic indicator. Only in one case was the SEP initially normal but could no longer be obtained at the age of 36 hours, at which stage the infant had a status epilepticus, resistant to extensive 
anticonvulsive treatment. It was more common for the SEP or VEP to normalise over the next 24-48 hours from a delayed to a normal latency, and this was associated with a good outcome in most of the infants. When the specificity was calculated at 72 hours of age, it had increased to $93.3 \%$ and $86.6 \%$ for the SEP and VEP, respectively. These findings agree with earlier data. ${ }^{23} 27$ The evoked responses are more time consuming to perform and provide little additional information compared with the CFM, which is now increasingly being used and which is easy to apply and interpret. ${ }^{152128}$

Except for the Apgar score, cord blood pH, and time of onset of spontaneous respiration, few data available within the first few hours of life have been evaluated as possible predictors of neurodevelopmental outcome. Wayenbergh et $\mathrm{al}^{42}$ found that a clinical score performed at 30 minutes of age and an arterial base excess measurement taken at this time were also good prognostic indicators of neurodevelopmental outcome. Data taken in the neonatal period in our infants were often incomplete, Apgar scores were not always recorded, and the first blood gas was often a capillary sample. We were therefore unable to compare our findings with those of Wayenbergh et al. ${ }^{42}$

In conclusion, the present data indicate that neurophysiology performed within the first six hours of life can reliably predict which infants will go on to develop moderate or severe encephalopathy and are subsequently likely either to die or develop adverse neurological sequelae. These tests may be of help in selecting infants who might benefit from neuroprotective agents.

We acknowledge the members of the European Neonatal Brain Club, in particular Dr J Rennie, Professor M I Levene, and Professor G Greisen, for their help in initiating this study.

Dr Paula Eken was supported by a grant from the Prinses Beatrix Fonds (No 92-2372).

1 Hagberg B, Hagberg G, Olow I. The changing panorama of cerebral palsy in Sweden. VI. Prevalence and origin during the birth year period 1983-1986. Acta Paediatrica 1993; 82: 387-93.

2 Sarnat HB, Sarnat MS. Neonatal encephalopathy following fetal distress. Arch Neurol 1976; 33: 696-705.

3 Levene MI, Kornberg J, Williams THC. The incidence and severity of postasphyxial encephalopathy in full-term infants. Early Hum Dev 1985; 11: 21-8.

4 Finer NN, Robertson CM, Richards RT, Pinnell LE, Peters $\mathrm{KL}$. Hypoxic-ischemic encephalopathy in term neonates. Perinatal factors and outcome. F Pediatr 1981; 98: 112-7.

5 Robertson C, Finer N. Term infants with hypoxicischaemic encephalopathy: outcome at 3.5 years. Dev Med Child Neurol 1985; 27: 473-84.

6 Dijxhoorn MJ, Visser GHJ, Huisjes HJ, Fidler V, Touren BLC. The relation between umbilical $\mathrm{pH}$ values and neonatal neurological morbidity in fullterm appropriate for date infants. Early Hum Dev 1985; 11: 33-73.

7 Ergander U, Eriksson M, Zetterstrom R. Severe neonatal asphyxia. Acta Paediatrica Scandinavica 1983; 72: 321-5.

8 Sykes GS, Johnson P, Ashworth F, Molloy PM, Gu W, Stirrat GM, Turnbull AC. Do Apgar scores indicate Stirrat GM, Turnbull AC. Do
asphyxia? Lancet 1982; i: 494-6.

9 Brain resuscitation clinical trial II study group. A randomized clinical study of a calcium-entry blocker (Lidoflazine) in the treatment of comatose survivors of cardiac arrest. $N$ Engl f Med 1991; 34: 1225-31.

10 Levene MI, Gibson NA, Fenton AC, Papathoma A, Barnett $D$. The use of a calcium channel blocker, nicardipine, for severely asphyxiated newborn infants. Dev Med Child Neurol 1990; 32: 567-74.

11 Desmedt JE, Brunko E, Debecker J. Maturation of the somatosensory evoked potentials in normal infants and children with special reference to the early N1 component. Electroencephalogr Clin Neurophysiol 1974; 40: 43-58.

12 Klimach V, Cooke RWI. Maturation of the neonatal somatosensory evoked responses in preterm infants. Dev Med Child Neurol 1988; 30: 208-14.

13 McCulloch DL, Taylor MJ, Whyte HE. Visual evoked potentials and visual prognosis following perinatal asphyxia. Arch Ophthalmol 1991; 109: 229-33.

14 Taylor MJ. Evoked potentials in paediatrics. In: Halliday AM, Ed. Evoked potentials in clinical testing. 2nd edn. Edinburgh: Churchill Livingstone, 1992.

15 Hellström-Westas L, Rosen I, Svenningsen NW. Predictive value of early continuous amplitude integrated EEG recordings on outcome after severe birth asphyxia in full term infants. Arch Dis Child 1995; 72: F34-8.

16 Griffiths R. The abilities of babies: a study in mental measure ment. Amersham: Association of Research in Infant and Child Development, 1976.

17 Amiel-Tison C, Grenier A. Evaluation neurologique du nouveau-né et du nourisson. Paris: Masson, 1980.

18 Touwen BLC. Examination of the child with minor neurological dysfunction. Clinics in Developmental Medicine No 71. London: SIMP/Heinemann, 1979.

19 Hagberg B, Hagberg G, Olow I. The changing panorama of cerebral palsy in Sweden. I: Analysis of general changes Acta Paediatrica Scandinavica 1975; 64: 187-92.

20 Archer LNJ, Levene MI, Evans DH. Cerebral artery Doppler ultrasonography for prediction of outcome after perinatal asphyxia. Lancet 1986; ii: 1116-8.

21 Bjerre I, Hellström-Westas L, Rosen I, Svenningsen N. Cerebral function monitoring in infants with severe asphyxia. Arch Dis Child 1983; 58: 997-1002.

$22 \mathrm{De}$ Vries LS. Somatosensory evoked potentials in term neonates with postasphyxial encephalopathy. Clin Perinatol 1993; 20: 463-82.

23 Gibson NA, Graham M, Levene MI. Somatosensory evoked potentials and outcome in perinatal asphyxia. Arch Dis Child 1992; 67: 393-9.

24 Levene MI, Fenton AC, Evans DH, Archer LNJ, Shortland DB, Gibson NA. Severe birth asphyxia and abnormal bB, Gibson NA. Severe birth asphyxia and abnormal blood-flow

25 Muttitt SC, Taylor MJ, Kobayashi JS, MacMillan L, Whyte $\mathrm{HE}$. Serial visual evoked potentials and outcome in term birth asphyxia. Pediatr Neurol 1991; 7: 86-90.

26 Pryds O, Greisen G, Lou H, Friis-Hansen B. Vasoparalysis is associated with brain damage in asphyxiated term infants. I Pediatr 1990; 117: 119-25.

27 Taylor MJ, Murphy WJ, Whyte HE. Prognostic reliability of SEPs and VEPs in asphyxiated term infants. Dev Med Child Neurol 1992; 34: 507-15.

28 Thornberg E, Ekstrom-Jodal B. Cerebral function monitoring: a method of predicting outcome in term neonates after severe perinatal asphyxia. Acta Paediatrica 1994; 83: 596-601.

29 Whyte H, Taylor MJ, Menzies R, Chin KC, MacMillan LJ. Prognostic utility of visual evoked potentials in term Prognostic utility of visual evoked potentials in te

30 Willis J, Duncan C, Bell R. Short-latency somatosensory evoked potentials in perinatal asphyxia. Pediatr Neurol 1987; 3: 203-7.

31 Babcock DS, Ball WB. Postasphyxial encephalopathy in fullterm infants: ultrasound diagnosis. Radiology 1983; 148: 417-23.

32 Martin DJ, Hill A, Fitz CR, Daneman A, Havill DA, Becker LE. Hypoxic-ischemic cerebral injury in the neonatal brain: a report of sonographic features with computed tomographic correlation. $\mathcal{f}$ Pediatr Radiol 1983; 13: 307-12.

33 Siegel MJ, Shackelford GD, Perlman JM, Fulling KH. Hypoxic-ischaemic encephalopathy in term infants: diagnosis and prognosis evaluated by ultrasound. Radiology 1984; 152: 395-9.

34 Gray PH, Tudehope DI, Masel JP, Burns YR, Mohay HA, O'Callaghan MJ, et al. Perinatal hypoxic-ischaemic brain O'Callaghan MJ, et al. Perinatal hypoxic-ischaemic brain injury: prediction

35 Baenziger O, Martin E, Steinlin M, Good M, Largo R, Burger $R$, et al. Early pattern recognition in severe perinatal asphyxia: a prospective MRI study. Neuroradiology 1993; 35: 437-42.

36 Kuenzle CH, Baenziger O, Martin E, Thun-Hohenstein L Steinlin M, Good M, et al. Prognostic value of early MR imaging in term infants with severe perinatal asphyxia. Neuropediatrics 1994; 25: 191-200.

37 Martin E, Barkovich AJ. Magnetic resonance imaging in perinatal asphyxia. Arch Dis Child 1995; 72: F62-70.

38 Couture A, Veyrac C, Baud C, Leboucq N, Montoya F. New imaging of cerebral ischaemic lesions. High frequency probes and pulsed Doppler. Ann Radiol 1987; 30: quency p

39 Eken P, Jansen GH, Groenendaal F, Rademaker K, de Vries LS. Intracranial lesions in the fullterm infant with
hypoxic ischaemic encephalopathy: ultrasound and hypoxic ischaemic encephalopathy: ultrasound and
autopsy correlation. Neuropediatrics 1994; 25: 301-7.

40 Rutherford MA, Pennock JM, Dubowitz LMS. Cranial ultrasound and magnetic resonance in imaging in hypoxic-ischaemic encephalopathy: a comparison with outcome. Dev Med Child Neurol 1994; 36: 813-25.

41 Bode H, Sauer M, Pringsheim W. Diagnosis of brain death by transcranial Doppler sonography. Arch Dis Child 1988; 63: $1474-8$.

42 Wayenberg J-L, Vermeylen D, Bormans J, Magrez P, Muller M-F, Pardou A. Diagnosis of severe birth asphyxia and early prediction of neonatal neurological outcome in term asphyxiated newborns. $\mathcal{F}$ Perinat Med 1994; 22: 129-36. 